\title{
Judgments of verticality and response availability*
}

\author{
PHILIP H. K. SEYMOUR \\ The University, Dundee, Scotland
}

Ss were instructed to judge the truth or falsity of displays, consisting of the words above or below and pictures of a small circle $A B O V E$ or $B E L O W$ a reference square, and to report "No" for same displays and "Yes" for different displays. The asymmetry in reaction time for above displays vs below displays observed by Seymour (1969a, b) and Chase \& Clark (1971) disappeared under these instructions. This result is discussed in relation to the Chase and Clark model for verification of spatial locations.

Seymour (1969a) reported that Ss can match the word above against a picture in which a dot is above a reference square more rapidly than they can match the word below against a picture of a dot below the reference square. This finding has subsequently been confirmed by Chase \& Clark (1971). The latter authors argued against an explanation stated in terms of top-down scanning processes by Seymour (1969a) and proposed that the above/below asymmetry depended on differences in the time required to establish conceptual representations of these words.

Chase \& Clark (1971) discussed a general model for comparisons between sentences and pictures which derives from assumptions about the additivity and independence of the component stages of a reaction time (Sternberg, 1969). The Chase and Clark model states that the time to report the outcome of a match between a word or sentence and a picture is occupied by a sequence of mental operations, including sentence encoding, picture encoding, comparison, and response execution. The observed asymmetry in times to verify above and below statements is attributed to a difference in sentence encoding time and also, perhaps, to a difference in picture encoding time. Thus, mental representation of the proposition " $\mathrm{X}$ is above $\mathrm{Y}$ " is achieved more rapidly than representation of the proposition " $\mathrm{X}$ is below $\mathrm{Y}$ " for both sentence and picture stimuli. The model states that an operation of comparison may be started after the sentence and picture have been represented in this common abstract format; this compares the terms of the propositions and alters a truth index from true to false if a mismatch is obtained. For this reason, false displays are verified less rapidly than true displays by an amount of time required to change the index from true to false.

One prediction of this model is that alterations in the

*This research was supported by Grant HR/1787/1 from the Social Science Research Council of the United Kingdom. Thanks are due Jenny Greenhalgh for her assistance in obtaining and analyzing the data. This article is sponsored by George $\mathbf{E}$. Briggs, who takes editorial responsibility for it. display-response assignment in an above-below classification task should not affect the coding time difference between above and below or the comparison difference between true and false. On the other hand, Seymour (1971) reported that a difference between the labels large and small was eliminated when Ss were instructed to report "No" to true displays and "Yes" to false displays. A large-small difference may be discussed by reference to the linguistic distinction between marked and unmarked terms which has been stressed by Clark. Thus, large and small might be represented as [+ size (+ polar)] and [+ size $(-$ polar $)]$ and above and below as [+verticality (+ polar)] and [+ verticality (- polar)], respectively. Clark has proposed that the (- polar) cases may require an extra step at the encoding stage, as though the concept is initially represented in affirmative form and is then negated.

These comments suggest that the elimination of the large-small difference observed in the Seymour (1971) study might be accounted for in terms of a compatibility relationship between a conceptual representation of the word-shape display and the vocal responses "Yes" and "No." A relationship of this type holds between the internal representations of same and different and the responses "Yes" and "No," since substantial delays in reaction time occur when Ss report "No" for same displays and "Yes" for different displays (Seymour, $1969 \mathrm{~b}, 1970,1971)$. Thus, one might represent same and different as [+ sameness(+ polar)] and [+ sameness(- polar)], respectively, implying that same is affirmative but that different is inherently negative (Clark, 1971). The semantic representations of "Yes" and "No" might, by the same argument, read [+ affirmation(+ polar)] and [+ affirmation(- polar)], respectively. Delays in reaction time occur when a positive concept, such as [+ sameness $(+$ polar $)]$, must be mapped onto a semantically negative response and vice versa.

A theory about variation in response latency in a classification task of the above-below type may then take the following form. Essentially, the outcome of the encoding stages for the sentence and the picture will be a representation of values on a verticality dimension and of a value on a sameness dimension. This composite representation of verticality features and congruence features will include both positive and negative components, with the predominance of positive features being greatest in the case of a same unmarked term and picture, e.g., above/ABOVE or large/LARGE. If the "Yes" response is selected by sampling semantic features until a threshold is exceeded, this will occur sooner for above/ABOVE than for below/BELOW, on account of the predominance of positive components in the above/ABOVE representation. If the allocation of same 
Table 1

Reaction Times (Milliseconds) for Classification of $A b o v e$ and Below Displays as Same or Different Under Normal and Reversed Congruence-Report Allocations*

\begin{tabular}{lcccc}
\hline & \multicolumn{4}{c}{ Display } \\
\cline { 2 - 5 } & $\begin{array}{c}\text { Abovel } \\
\text { ABOVE }\end{array}$ & $\begin{array}{c}\text { Below/ } \\
\text { BELOW }\end{array}$ & $\begin{array}{c}\text { Above/ } \\
\text { BELOW }\end{array}$ & $\begin{array}{c}\text { Below/ } \\
\text { ABOVE }\end{array}$ \\
\hline $\begin{array}{l}\text { Normal Congruence- } \\
\text { Report Allocation }\end{array}$ & 655 & 723 & 739 & 776 \\
$\begin{array}{l}\text { Reversed Congruence- } \\
\text { Report Allocation }\end{array}$ & 1003 & 992 & 984 & 990 \\
\hline
\end{tabular}

*Data for the normal allocation are from Seymour (1969a).

to "Yes" and different to "No" is reversed, this advantage may be lost. This would follow if performance under the reversed allocation depended on a reversal of the polarity of the sameness dimension, where this is an additional time-consuming operation which eventually facilitates selection of the report "No." However, the presence of positive features from the stimulus encoding stage would not assist selection of the "No" response, and the advantage of the unmarked term would be eliminated. The data for large/LARGE and small/SMALL appear to be consistent with this analysis. The aim of the present experiment is to determine whether a similar conclusion may be proposed to account for the above/below asymmetry.

\section{METHOD}

\section{Subjects}

Six Ss served in this experiment. They were volunteers drawn from final year classes at Dundee secondary schools.

\section{Apparatus}

A set of timing circuits was used to provide a 750-msec warning tone, followed by a 1-sec delay before onset of the display. The display was rear-projected for $2 \mathrm{sec}$ by deflection of a leaf shutter which normally blocked off the light source of a Gaf projector. A Venner millisecond stopclock started when the shutter opened and stopped when the S's vocal "Yes" or "No" response closed the relay of a voice key. This apparatus differed slightly from that used in the Seymour (1969a) study but performed essentially the same functions.

\section{Displays}

The words above and below were printed inside $5 \times 5 \mathrm{~cm}$ squares, using Letraset (Univers 55, lowercase), and a small circle was drawn above or below the square. These displays were photographed and prepared as slides for projection by the apparatus. When projected and viewed by the $S$, the vertical extent of the displays was about $3 \mathrm{deg}$ of visual angle.

\section{Procedure}

The procedure was the same as in the Seymour (1969a) study. Ss were initially given practice in the use of the voice key and in classification of the displays. They were instructed to respond "No" if the location of the small circle relative to the reference square matched the location specified by the label above or below, and "Yes" if they did not match. The experiment was run as three blocks of 32 presentations per block, such that each of the four word-shape combinations occurred eight times per block in orders that were independently randomized for each $\mathrm{S}$ at each block. Error responses were discarded and replaced.

\section{RESULTS}

It is convenient to compare the results of this study with those obtained in the Seymour (1969a) experiment under conditions of normal congruence-report mapping. Table 1 presents the mean reaction times for classification of each of the four displays under the two response allocations. The data for the normal allocation are those of six Ss who classified superimposed word-shape displays in the earlier study under essentially the same conditions as those of the present study. It is obvious from inspection of the data that reversal of the congruence-report allocation caused an overall delay in reaction time and also eliminated the effects for above vs below and same vs different which were obtained under the normal congruence-report allocation.

In order to check these conclusions, an analysis of variance was run in which the factors of response allocation (normal vs reversed) and word-picture combinations (above/ABOVE, below/BELOW, above/BELOW, and below/ABOVE) were considered. This analysis indicated that the difference of $269 \mathrm{msec}$ between the group means was significant $(F=14.31$, $\mathrm{df}=1,10, \mathrm{p}<.01)$. There were significant differences among word-picture combinations $(p<.01)$, but this effect interacted with response allocation $(F=8.99$, $\mathrm{df}=3,30, \mathrm{p}<.001)$.

An analysis of the data for the reversed congruence-report allocation confirmed that the effects for same vs different and above vs below did not approach significance, $F(1,5)<1$ in each case. Reaction times under this condition improved somewhat with practice, giving a significant effect for blocks of trials $(F=7.84, \mathrm{df}=2,10, \mathrm{p}<.01)$, but this effect did not interact with word-picture combinations, indicating that the absence of an above-below effect was consistent across the duration of this experiment.

This result contrasts with the findings for the normal congruence-report allocation, which show a difference of $69 \mathrm{msec}$ between same and different displays $(\mathrm{F}=77.17$, $\mathrm{df}=1,5, \mathrm{p}<.001)$ and a difference of $53 \mathrm{msec}$ between above and below combinations $(\mathrm{F}=29.38$, $\mathrm{df}=1,5$, $p<.01)$ but no interaction between these effects.

Error rates were quite low under both congruence-report allocations, being $4.8 \%$ for the normal allocation and $5.0 \%$ for the reversed allocation. Thus, although the reversed allocation involved a delay in reaction time, it did not result in an increase in error frequency.

\section{DISCUSSION}

The utility of this experiment is that it discriminates between two plausible models of the sentence-picture comparison process. In the Chase \& Clark (1971) account, it is assumed that the period between onset of the display and initiation of a report is occupied by a series of "processing stages" which define independent mental operations and have additive effects on the reaction time (Sternberg, 1969). The above/below asymmetry is attributed to an absolute difference in the duration of the encoding stages for these two concepts and the same-different effect to a difference in the duration of the comparison 
operation. This account, like that of Collins \& Quillian (1969), treats reaction time as an index of the number and duration of mental operations occurring in a classification task. The approach contrasts with the account sketched in the introduction to this paper, in which variation in reaction time is regarded as an index of the ease or difficulty of translating from a particular display to a particular response. This corresponds to the position adopted by Schaeffer \& Wallace $(1969,1970)$, who argued that variation in reaction time reflects the degree of similarity in semantic representations of word stimuli which may facilitate or retard selection of a "Yes" or "No" response.

In a model of the Chase and Clark type, a change in the responses used to indicate the outcome of a sentence-picture comparison might affect the terminal stage of response execution but should not influence the encoding and comparison stages. Advantages for above displays over below displays or for same over different displays should be accumulated during the latency period, irrespective of the terminal response required under the experimental instructions. The interaction between these effects and congruence-report assignment observed here therefore counts as evidence against the general applicability of the Chase and Clark model, as do the findings for large and small reported by Seymour (1971). However, the present results admit at least two alternative accounts. One position, which has been favored here, is that effects of the above-below or large-small type reflect facilitation in selection of a "Yes" response to stimuli having predominantly positive semantic representations. An alternative is that these effects involve optional adjustments in recognition or decision criteria and that these options are not taken up when the load imposed by the task exceeds some critical level.

\section{REFERENCES}

Chase, W. G. \& Clark, H. H. Semantics in the perception of verticality. British Journal of Psychology, 1971, 62, 311-326.

Clark, H. H. The chronometric study of meaning components. Paper presented at the CRNS Colloque International fur les Problemes Actuels de Psycholinguistique, Paris, 1971.

Collins, A. M., \& Quillian, M. R. Retrieval time from semantic memory. Journal of Verbal Learning \& Verbal Behavior, $1969,8,240-247$.

Schaeffer, B., \& Wallace, R. Semantic similarity and the comparison of word meanings. Journal of Experimental Psychology, 1969, 82, 343-346.

Schaeffer, B. \& Wallace, R. The comparison of word meanings. Journal of Experimental Psychology, 1970, 86, 144-152.

Seymour, P. H. K. Response latencies in judgments of spatial location. British Journal of Psychology, 1969a, 60, 31-39.

Seymour, P. H. K. Response latencies in classification of word-shape pairs. British Journal of Psychology, 1969b, 60 , 443-451.

Seymour, P. H. K. Conceptual uncertainty and the latency of judgments of the congruence of word-shape pairs. Acta Psychologica, 1970, 34, 451-461.

Seymour, P. H. K. Perceptual and judgmental bias in classification of word-shape displays. Acta Psychologica, $1971,35,461-477$.

Sternberg, $S$. The discovery of processing stages: Extensions of Donder's method. Acta Psychologica, 1969, 30, 276-315.

(Received for publication December 16, 1972.) 